\title{
The Effectiveness of Cognitive Behavioral Therapy Including Updating the Early Life Experiences and Images with the Empty Chair Technique on Social Anxiety
}

\author{
Volkan Avsar (iD),*, Seher A. Sevim (iD) 2
}

\author{
${ }^{1}$ Recep Tayyip Erdogan University, Faculty of Education, Department of Educational Sciences, Guidance and \\ Psychological Counseling, Rize, Turkiye \\ ${ }^{2}$ Independent Researcher
}

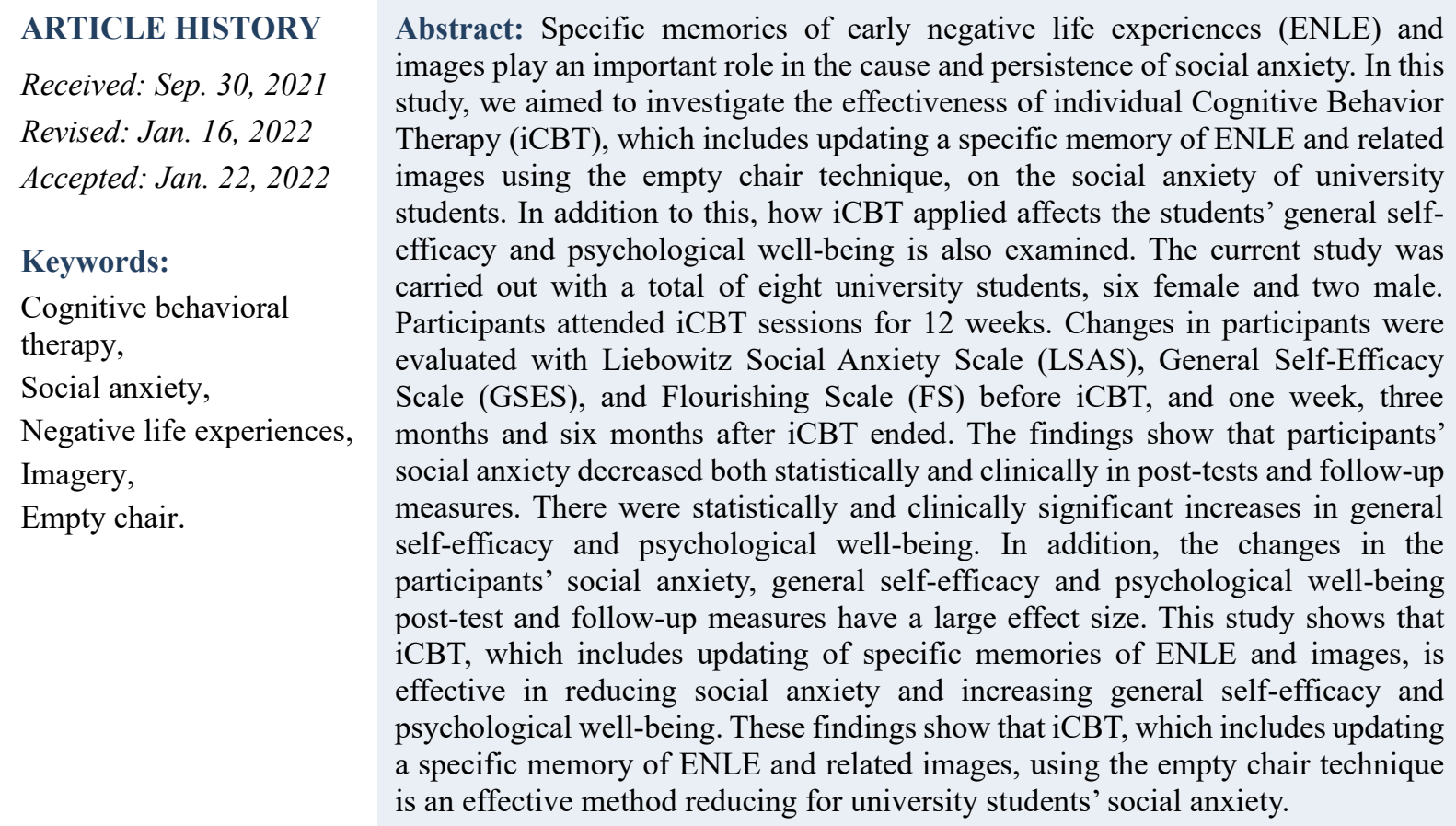

\section{INTRODUCTION}

Social anxiety is a common mental health problem that causes significant functional impairment (Aderka et al., 2012). Its yearly prevalence in the general population is between $2 \%$ and 7.4\% (Fehm et al., 2008; Kessler et al., 2012), while its lifetime prevalence is between 3.1\% and $12.1 \%$ (Faravelli et al., 2000; Ruscio et al., 2008). The pervasiveness rate among university students ranges from 11.6\% to 36.3\% (Baptista et al., 2012; Regis et al., 2018). Among university students in Turkey, the yearly rate is between $7.9 \%$ to $20.9 \%$, and the lifetime rate is between $9.6 \%$ to $21.7 \%$ (Gultekin \& Dereboy, 2011; Izgic et al., 2004). This problem, which is also common among students, negatively affects their relationships, functionality, quality of

\footnotetext{
*CONTACT: Volkan AVSAR \volkan.avsar@erdogan.edu.tr of Education, Department of Educational Sciences, Guidance and Psychological Counseling, Rize, Turkiye
} 
life, education and career, and adaptation to university, preventing them from benefiting from university life adequately (Brook \& Willoughby, 2015; Ghaedi et al., 2010; Nordstrom et al., 2014).

Social anxiety is negatively related to people's general self-efficacy (Rudy et al., 2012). General self-efficacy includes the individual's belief in coping skills in the face of difficulties (Luszczynska et al., 2005; Scherbaum et al., 2006; Schwarzer, 1994). In other words, people with high general self-efficacy have confidence in their ability to cope with the difficulties they face. According to Bandura (1977a), having a functional coping skill contributes positively to the sense of self-efficacy. For this reason, individuals' experiences in which they can use their skills successfully will increase their sense of self-efficacy (Bandura, 1977b). Such experiences include the use of cognitive and behavioral interventions (behavioral such as exposure), which are the basic components of Cognitive Behavior Therapy (CBT) in anxiety-provoking situations for individuals with social anxiety (Gordon et al., 2014; Holaway \& Heimberg, 2004). Belief in self-efficacy is also associated with cognitive change and behavioral change (Bandura, 1997). It is stated that exposure to certain situations particularly increase self-efficacy (Biran \& Wilson, 1981). As a result, it can be said that cognitive and behavioral interventions to be applied for social anxiety may also lead to an increase in general self-efficacy feelings.

Studies show that people with social anxiety also have low psychological well-being (Fava et al., 1998; Kashdan et al., 2006; Wang et al., 2014; Wersebe et al., 2018). Psychological wellbeing point to the experience of life going well (Huppert, 2009) and realization of one's true potential (Ryff, 1989b). Psychological well-being is the combination of feeling good and functioning effectively. In other words, it includes experiencing both positive emotions of happiness and contentment, and negative or painful emotions that are a natural part of life and being functional enough to cope with them (Huppert, 2009). According to (Ryff, 1989a), effective functioning is important for psychological well-being. The reason is that when negative emotions last excessively or for too long and the functionality of the person in their daily life is negatively affected, psychological well-being is compromised (Huppert, 2009). Social anxiety is a persistent problem (Kring \& Johnson, 2014). People with social anxiety show significant functional impairments (Aderka et al., 2012; Maner \& Kenrick, 2010). In addition, these individuals have dysfunctional cognitive and behavioral strategies (McManus et al., 2008; Mellings \& Alden, 2000). It can be said that these situations, which prevent them from realizing their potential, also affect their psychological well-being. Consequently, it can be said that since the cognitive and behavioral interventions that will be applied to people so that they can cope with their social anxiety will improve their functionalities, it may also increase their psychological well-being.

The fact that social anxiety starts from an early age and develops slowly (American Psychiatric Association, 2013), becomes persistent when not intervened, and causes significant deterioration in academic, professional, and social functionality by affecting the later years of life draw the attention to childhood years (Vassilopoulos, 2012). Childhood years is a period when social life begins, life-oriented learning is intense, and memories that may affect the later stages of life are formed. Negative life experiences in childhood have a unique effect on the onset of social anxiety (Magee, 1999). People with social anxiety develop a series of assumptions, dysfunctional beliefs, and negative self-images about themselves and their social world based on their early negative life experiences in these years (Clark, 2001). Studies have shown that negative early life experiences are also common among university students with high social anxiety (Binelli et al., 2012), and that these people mostly have negative and social anxiety-related memories (Krans et al., 2014).

Clark and Wells' (1995) social anxiety model has simplified the understanding of the cognitive and behavioral components that cause the maintaining of social anxiety. This model claims that 
the self-focused attention, safety behaviors, and their dysfunctional beliefs about themselves and their social world as the main components that maintain social anxiety. Another important point that the model focuses on is mental imagery. People with social anxiety generally have negative self-images in relation to negative self-beliefs (Wild \& Clark, 2015). Such people, who focus on how they make an impression on others, especially in feared social situations, experience extremely negative images of themselves. Using these images, they make biased and erroneous inferences about how they are seen by others (Clark \& Wells, 1995). Hackmann et al. (1998) confirm that people with social anxiety experience negative, distorted, observerperspective images in social environments where their anxiety is activated. Socially anxious people with negative images experience high levels of anxiety, believe that their anxiety is seen by others, and evaluate their performance negatively. They also use more safety behaviors, have more negative thoughts, and are more self-focused (Hirsch et al., 2004; Makkar \& Grisham, 2011).

Negative images commonly seen in people with social anxiety play a causal role in the development and maintaining of social anxiety (Hirsch et al., 2003; Hirsch et al., 2006). Negative images are related to negative life experiences during the onset of social anxiety (Hackmann et al., 2000; Kuo et al., 2011; Stopa \& Jenkins, 2007; Wild \& Clark, 2011). Therefore, social anxiety interventions should focus on updating the mental representation images of early negative life experiences (Knutsson et al., 2020).

People with social anxiety commonly experience negative, recurrent, and intrusive images in anxiety-provoking social situations (Hackmann et al., 2000; Wild et al., 2007, 2008). In other words, images are activated again and again following the onset of social anxiety. Even if the person experiences positive experiences in social situations in the later years of their life, they cannot develop new perspectives and update themselves due to the activation of images (Hackmann et al., 2000). In order to cope with social anxiety, these negative images, which play a key role in the maintaining of social anxiety, need to be updated (Wild \& Clark, 2011). Updating the images will have a strong effect on the emotional processing and change of meaning of early life experiences (Arntz, 2011). In summary, recurrent and intrusive memories of earlier negative life experiences and images associated with present social anxiety is seen. Therefore, it is important to modify and update the early negative life experiences and the images which are mental representations of these early life experiences.

There are many studies in the literature showing that CBT, which includes early negative life experiences and updating the images, is effective for social anxiety (Knutsson et al., 2020; Lee \& Kwon, 2013; Nilsson et al., 2012; Norton \& Abbott, 2016; Norton et al., 2021; Romano et al., 2020; Wild et al., 2007, 2008). During the counseling process, CBT also makes use of techniques from other theories (Harwood et al., 2010; Howes \& Parrott, 1991). While updating negative life experiences and images, the "empty chair" technique from Gestalt Therapy (GT) can also be used. It is stated that this technique can be combined with CBT in order to increase the affect, reveal the cognitions of the participants, and for purposes of cognitive restructuring (Arnkoff, 1981; Kellogg, 2004). According to Paivio et al. (2001), the impact of early negative life experiences and emotions can be reduced by internalizing new information and developing new perspectives. With the empty chair technique, people can express their feelings, thoughts and needs to people with whom they have problems, even if it is imaginary. Eventually, this contributes to the development of new understandings and new perspectives about themselves, the people with whom they have problems and their negative lives. It also helps to finish unfinished business (Greenberg, 2010). It is thought that an individual CBT (iCBT), in which Clark and Wells' (1995) social anxiety model is included, and specific memories of early negative life experiences and related images are updated with the empty chair technique, will be effective in coping with social anxiety. 
The aim of this study is to investigate the effectiveness of iCBT, in which a specific memory of early negative life experiences and related images will be modified and updated using the empty chair technique, on the social anxiety of university students. In addition, the effect of iCBT applied on university students' general self-efficacy and psychological well-being is also examined. The research hypotheses formed in line with the aims of the research are as follows:

1. The social anxiety pre-test scores of the participants are higher than the post-test, follow-up 1 and follow-up 2 scores.

2. The general self-efficacy pre-test scores of the participants are lower than the post-test, follow-up 1 and follow-up 2 scores.

3. The psychological well-being pre-test scores of the participants are lower than the post-test, follow-up 1 and follow-up 2 scores.

\section{METHOD}

\subsection{Research Model}

This study was carried out in the one group pre-test - post-test design, which is one of the poor experimental designs. The current study design is shown at Table 1.

Table 1. Study design.

\begin{tabular}{cccccc}
\hline Participants & Pre-test & $\mathrm{X}$ & Post-test & Follow-up 1 & Follow-up 2 \\
\hline $\mathrm{P}$ & $\mathrm{O}_{1}$ & Intervention & $\mathrm{O}_{2}$ & $\mathrm{O}_{3}$ & $\mathrm{O}_{4}$ \\
\hline
\end{tabular}

\subsection{Participants}

This study was approved by the Blinded University Ethics Committee (85434274050.04.04/6260). In order to determine the participants, the necessary legal permission was obtained from the university where the application will be made (72940495-900/1203). Following the permission, the Social Anxiety Scale (SAS) developed by Özbay and Palanc1 (2001), was applied to 933 undergraduate students studying in seven different departments (see Figure 1). While settling the participants who will participate in the study, 33 students with high social anxiety were contacted for a preliminary interview. Among those, students who are in their last year were not included in the pre-interview so as not to prevent the possible effects of situations such as graduation, worries around finding a job, and preparing for national exams.

While giving information about the research process to 17 students who participated in the preliminary interview, the researcher also collected information about the students' personal problems, eligibility for work and motivation level. The information obtained in the preliminary interview was evaluated in terms of inclusion and exclusion criteria, which were created to identify the participants. The inclusion criteria of the study consisted of: (a) A score of 80 or more in SAS, which is two standard deviations above the mean, (b) Having the motivation to cope with social anxiety, (c) Accepting the recording of the sessions, (d) Signing the Informed Consent form, (e) To be able to participate actively and continuously in the study process. Individuals were excluded if: (a) There is another psychological problem accompanying social anxiety, (b) There are people with a serious physical health or psychological problem in their family or close circle, (c) The participant has received or is still receiving counseling near the time of the study, (d) They use medication due to social anxiety.

As a result of the preliminary interview, eight students who met the inclusion criteria were included in the study. Detailed information about the process (meeting place and time, duration and number of sessions, confidentiality, recording sessions etc.) was given to these people. In addition, the Liebowitz Social Anxiety Scale (LSAS), General Self-Efficacy Scale (GSES) and Flourishing Scale (FS) were applied to the participants before the counseling process started, and one week, three months and six months after the counseling process ended. 
Figure 1. The flowchart of determining of the participants and the process.

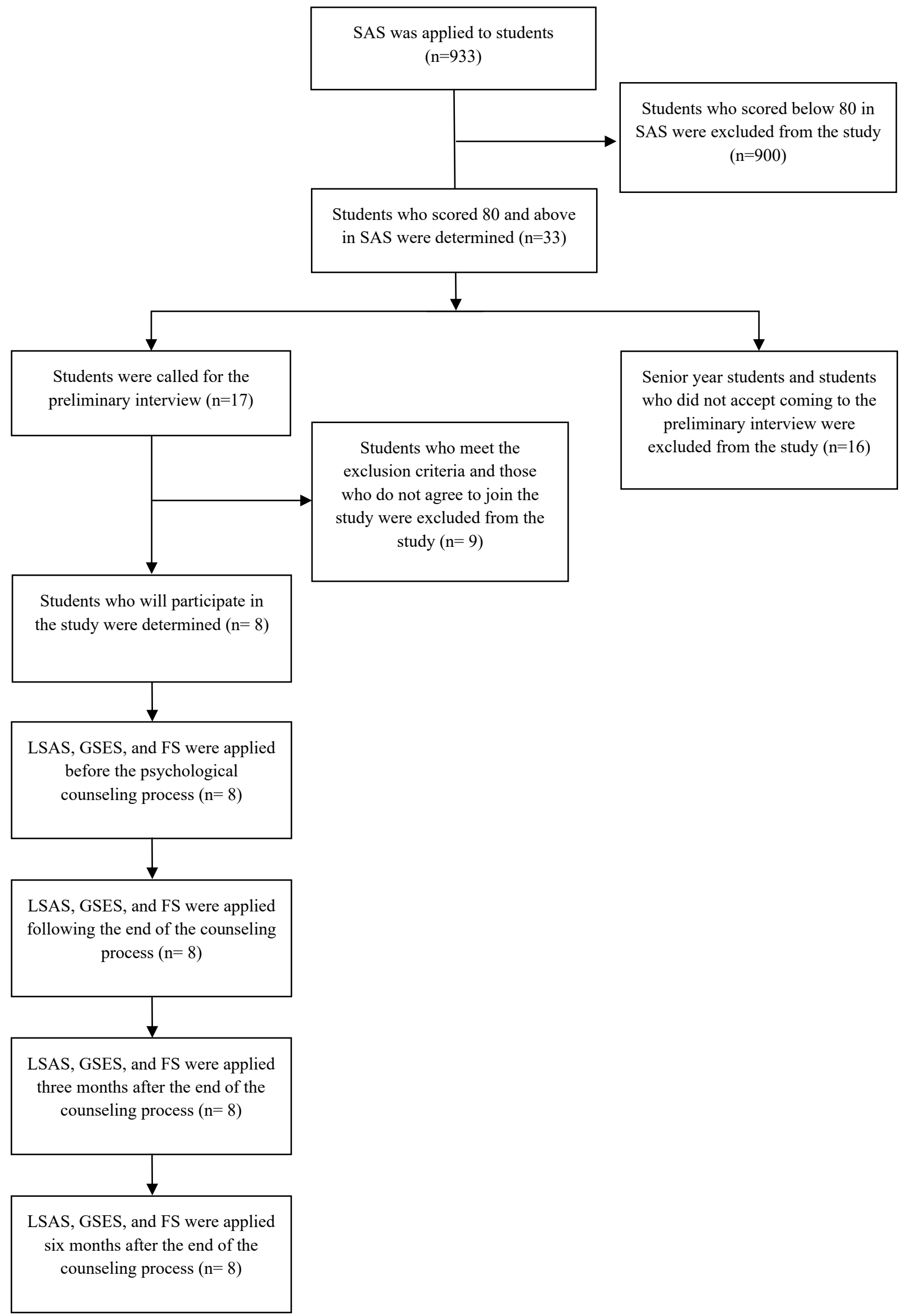




\subsection{Counseling Process and Sessions}

For the participants to cope with social anxiety, iCBT procedure which consists of 12 face-toface sessions are structured. The fact that the participants were university students was influential in limiting iCBT to 12 sessions. It was aimed to conclude the iCBT in one semester in order to avoid secondary variables that may appear during the semester break and affect the research results. The structured sessions are presented to three academicians who are experts in the field of CBT, their opinions are collected and the final version of the iCBT procedure is formed. The duration of each session is 50 minutes. However, the first session in which the participants' issues are evaluated as well as the fourth session in which a specific memory of negative life experiences and related images are re-evaluated are determined as 90 minutes as per their content. The application of the structured counseling process is carried out by the first author of the research, who has a CBT training. Throughout the procedure, training and regular supervision from experienced CBT supervisors is received.

In Session 1, it is aimed to evaluate, conceptualize the problem and create a therapeutic alliance. Within that framework, when the participants' history of the problem is recorded the beliefs, thoughts, emotions, behaviors and physiological symptoms are identified. A specific memory of early negative life experiences and images that may be associated with the participants' problems are also pinpointed. How the problem affects the life of participants is evaluated.

In Session 2, the focus is on psycho-education, goal setting and conceptualization of the problem. Participants are primarily informed about the general structure of the sessions and agenda setting. Then, the objectives that the participants want to achieve at the end of the process are determined. Then, the formulations of the participants are carried out using the social anxiety model of Clark and Wells (1995).

In Session 3, the focus is on how the participants' automatic thoughts, cognitive distortions and safety behaviors relate to their problem and their affect on the maintenance of this issue.

In Session 4, a specific memory of early negative life experiences related to the participants' problem, the meaning they ascribe to this memory and images are identified, and are reevaluated using the empty chair technique.

In the first step of addressing negative experiences, participants' memories from their childhood years that affect them and cause them to experience negative emotions when they remember them were discussed in general terms. Memories that participants told were listed under titles, and the participants were asked to determine the memory that they deem is related to their issue and one that affect them the most. Later on, their beliefs, thoughts, emotions, images related to this experience and the extent to which they are affected by this experience was discussed. In the second step, participants' discovery of how their negative experiences affect the later years of their lives, their relationships, and how it is related to their problem was focused on.

In the third step, memories specified by the participants were addressed in two stages, using the empty chair technique. Memories participants focused on in the first stage of the application were revived as if they were being experienced again at that current time. With the help of empty chair technique, participants were facilitated to express their emotions, thoughts and images by creating dialogues with the people they experienced the issue. After the participants expressed their emotions, thoughts and images, they took the place of the person who caused the negative experience by taking the empty chair facing them. They responded as that person in response to what they said as themselves. In this way, the participants had the opportunity to express their feelings, thoughts and images by experiencing them. Also, by taking the place of the person in front of them, they had the opportunity to evaluate their life and images from the perspective of the other person in a way that they had not evaluated before. 
In the second stage of the application, participants evaluated their experience as their current adult self and as a child who had the experience. Within this framework, their reactions as a child who encountered that situation at the time were elaborated. How the child self-evaluated the issue and the limitations of their reactions as a child were discussed. Later, it was focused how their current adult self would evaluate the situation and how they would react. During this application, the participants were facilitated to discover the difference between children and adults in terms of giving reaction. In the fourth and final step after the participants re-evaluated a specific memory of early negative life experiences and images, it was focused whether they discovered something about their life they had not noticed before or had just noticed, or whether they gained new perspectives. It was addressed whether there was any change or difference in the meaning they attribute to their memories, images, emotional processing, and beliefs.

In Sessions 5, 6 and 7, the beliefs of the participants about their problems were determined based on the agenda, and cognitive interventions were carried out for the determined beliefs. During these interventions, what the participants learned in the fourth session was also utilized.

In Session 8, the avoidance and safety behaviors of the participants were discussed, and the rationality of exposure and habituation, its place and importance in coping with the problem were evaluated.

In Sessions 9, 10, and 11, cognitive and behavioral interventions were carried out simultaneously. Cognitive and behavioral techniques were used together to intervene on the agenda items determined together with the participants. In these sessions, participants were exposed to these situations they avoid that are related to their problem during the session as well as their daily life. Interventions were made during the session, particularly through behavioral experiments, video feedback, and real and gradual exposure.

In Session 12, the process was concluded.

\subsection{Data Collection Instruments}

\subsubsection{Liebowitz social anxiety scale}

LSAS, which was developed by Liebowitz (1987) and which consists of 24 items, evaluates the anxiety or avoidance levels in different social and performance situations. Each item in the scale is given an individual score from one to four for anxiety and avoidance dimensions. Adapted to Turkish culture by Soykan et al. (2003), the reliability of LSAS is calculated to be 0.97 for the whole scale via test and re-test method. The Cronbach Alpha reliability coefficient in terms of internal consistency is found to be 0.98 for the whole scale, 0.96 for the anxiety dimension, and 0.95 for the avoidance dimension. In this study, the Cronbach Alpha reliability coefficient of LSAS was calculated to be 0.95 for the whole scale, 0.91 for the anxiety dimension, and 0.89 for the avoidance dimension.

\subsubsection{Social anxiety scale}

SAS was developed by Özbay and Palanc1 (2001) to identify the social anxiety related problems of university students. The scale consists of 30 items and has a five-point rating within the range of $0-4$. For the reliability of the scale, the Cronbach Alpha internal consistency coefficient was calculated as 0.89. In this study, the Cronbach Alpha reliability coefficient of SAS was calculated to be 0.93 .

\subsubsection{General self-efficacy scale}

GSES was developed by Schwarzer and Jerusalem (1995) to determine people's efficacy belief in coping with stressful and challenging life events. The scale consists of 10 items and has a four-point rating. The scale was adapted to Turkish culture by Aypay (2010). The reliability of the scale was researched via test and re-test method and the Cronbach Alpha internal consistency coefficient. Test re-test reliability coefficient was calculated as 0.80 , and the 
Cronbach Alpha reliability coefficient was calculated as 0.83 . In this study, the Cronbach Alpha reliability coefficient of GSES was calculated to be 0.89 .

\subsubsection{Flourishing scale}

FS, which was developed by Diener et al. (2010) to measure the psychological well-being, consists of eight items. The items in the scale has seven-point rating. The scale was adapted to Turkish culture by Telef (2013). The reliability of the scale was researched via test and re-test method and the Cronbach Alpha internal consistency coefficient. Test re-test reliability coefficient was calculated as 0.86 , and the Cronbach Alpha internal consistency coefficient was calculated as 0.80 . In this study, the Cronbach Alpha reliability coefficient of FS was calculated to be 0.88 .

\subsection{Statistical Analyses}

For the purpose of the study, whether there is a statistically significant difference between the mean scores of the pre-test, post-test and follow-up scores obtained from the scales applied to the participants was analyzed via the Friedman test. Furthermore, in order to analyze whether there was a statistically significant difference between the pretest-posttest, pretest-follow-up 1 and pretest-follow-up 2 scores of the participants, the Wilcoxon Signed Rank Test was used. The effect size of the existing difference was calculated with the formula in equation 1 (Rosenthal, 1991).

$$
r=\frac{|z|}{\sqrt{N}}
$$

(Equation 1)

In addition, the clinical significance of the change in participants was evaluated in this study. Two conditions need to be met in order to determine the clinical significance of the change observed in the participants as a result of the intervention. According to the first of the two conditions, the participants in the dysfunctional population before the intervention must be transferred to the functional population after the intervention. While determining this transition, the cut-off score of the measurement tool used before and after the intervention is used. In other words, the post-test scores of the person need to surpass the cut-off point threshold. In cases where there is no cut-off point for the measurement tools, a cut-off point is calculated for the measurement tools. Since there were no cut-off scores for the measurement tools used in this study, cut-off scores were generated (Bauer et al., 2004; Jacobson \& Truax, 1991). In accordance with this, the cut-off scores for LSAS were 84; 26 for GSES; and 43 for FS. According to the second condition, the change in the person who exceeds the cut-off score should be statistically reliable. And this is evaluated using the "Reliable Change Index (RCI)" (Jacobson et al., 1984; Jacobson \& Truax, 1991).

If the RCI is above $\mp 1.96$, it shows that the change observed in the person is reliable, while a range of $\mp 1.96$ indicates that the change is unreliable (Jacobson \& Truax, 1991). The change observed in people using RCI and cut-off scores is evaluated in four categories (Atkins et al., 2005):
a. Recovered (Meets both RCI and cut-off score criteria)
b. Improved (Meets RCI criteria but not cut-off score criteria)
c. Unchanged (Does not meet neither RCI nor cut-off score criteria)
d. Deteriorated (Meets RCI criteria but deteriorated) 


\section{RESULTS}

\subsection{Participants' Baseline Characteristics}

The demographics of the participants is given in Table 2. When examined, it is seen in Table 2 that most of the participants are women (6 female, 2 male participants). Additionally, the participants come from different departments and grade levels.

Table 2. Participants' baseline characteristics.

\begin{tabular}{llc}
\hline Variable & Level & Frequency (f) \\
\hline Gender & Female & 6 \\
\cline { 2 - 3 } & Male & 2 \\
\hline Age & 18 & 3 \\
& 19 & 1 \\
& 20 & 2 \\
& 21 & 2 \\
\hline Grade Level & 1 & 4 \\
& 2 & 3 \\
& 3 & 1 \\
\hline Department & School Teaching & 3 \\
& Psychological Counseling and Guidance & 2 \\
& Science Teaching & 1 \\
& Turkish Teaching & 1 \\
& Computer and Instructional Technologies Teaching & 1 \\
\hline Total & & 8 \\
\hline
\end{tabular}

\subsection{Treatment Effects}

The average and standard deviations of the participants' pre-test scores from LSAS, GSES and FS and their post-test, follow-up 1 (3 months), follow-up 2 (6 months) scores are given in Table 3 .

Table 3. Descriptive statistics of study variables across counseling conditions.

\begin{tabular}{lcccccccc}
\hline & \multicolumn{2}{c}{ Pre-treatment } & \multicolumn{2}{c}{ Post-treatment } & \multicolumn{2}{c}{ Follow-up 1 } & \multicolumn{2}{c}{ Follow-up 2 } \\
\cline { 2 - 9 } Measures & $M$ & $S D$ & $M$ & $S D$ & $M$ & $S D$ & $M$ & $S D$ \\
\hline LSAS & 108.12 & 12.13 & 45.62 & 19.54 & 37.87 & 8.37 & 38.62 & 10.88 \\
GSES & 18.00 & 4.10 & 33.12 & 4.54 & 31.62 & 3.77 & 30.87 & 5.43 \\
FS & 24.50 & 9.33 & 46.75 & 4.26 & 47.37 & 3.58 & 46.12 & 7.21 \\
\hline
\end{tabular}

Note. LSAS = Liebowitz Social Anxiety Scale; GSES = General Self-Efficacy Scale; FS = Flourishing Scale.

When Table 3 is examined, it is seen that the social anxiety of the participants decreased after the iCBT and in the follow-up measurements compared to the pre-test measurements. Their general self-efficacy and psychological well-being, however, increased after iCBT and in follow-up measurements compared to pre-test measurements. Whether the difference between the scores is statistically significant is determined via the Wilcoxon Signed Rank Test, and the acquired results are given in Table 4. Also, the values obtained from the comparison of the measurements taken at three different times (Pre-test - Post-test/Pre-test - Follow-up 1/Pre-test - Follow-up 2) from three different measurement tools (LSAS, GSES, and FS) are the same and are included in Table 4. In addition, the RCI results calculated to reveal the clinical significance of the changes in the social anxiety, general self-efficacy and psychological wellbeing of the participants are included in Table 5, Table 6 and Table 7, respectively. 
Table 4. The comparison of the participants' pre-test scores and post-test, follow-up 1 and follow-up 2 scores.

\begin{tabular}{|c|c|c|c|c|c|c|c|}
\hline \multirow[b]{2}{*}{ Measures } & & \multirow[b]{2}{*}{$n$} & \multicolumn{5}{|c|}{ Pre-test-Post-test/Pre-test-Follow-up 1/Pre-test-Follow-up 2} \\
\hline & & & $\bar{X}$ rank & $\sum$ rank & $z$ & $p$ & $r$ \\
\hline \multirow{4}{*}{ LSAS } & Negative Ranks & 8 & 4.50 & 36.00 & $-2.52^{* *}$ & $0.012^{*}$ & 0.89 \\
\hline & Positive Ranks & 0 & 0.00 & 0.00 & & & \\
\hline & Ties & 0 & & & & & \\
\hline & Total & 8 & & & & & \\
\hline \multirow{4}{*}{ GSES } & Negative Ranks & 0 & 0.00 & 0.00 & $-2.52^{* * *}$ & $0.012^{*}$ & 0.89 \\
\hline & Positive Ranks & 8 & 4.50 & 36.00 & & & \\
\hline & Ties & 0 & & & & & \\
\hline & Total & 8 & & & & & \\
\hline \multirow{4}{*}{ FS } & Negative Ranks & 0 & 0.00 & 0.00 & $-2.52^{* * *}$ & $0.012^{*}$ & 0.89 \\
\hline & Positive Ranks & 8 & 4.50 & 36.00 & & & \\
\hline & Ties & 0 & & & & & \\
\hline & Total & 8 & & & & & \\
\hline
\end{tabular}

Note. ${ }^{*} p<.05 ;{ }^{* *}$ Based on positive ranks; ${ }^{* * *}$ Based on negative ranks; $r$ : Effect size

When Table 4 is examined, it is seen that the difference between the participants' LSAS pretest scores and post-test, follow-up 1 and follow-up 2 scores is statistically significant $(z=-2.52$, $p<.05)$. The participants' social anxiety pre-test scores are higher than their post-test, followup 1 and follow-up 2 scores. The effect size of this existing difference is large $r=0.89 ; 95 \%$ confidence interval [CI: .49, .98].

It is seen that the difference between the participants' GSES pre-test scores and post-test, follow-up 1 and follow-up 2 scores is statistically significant $(z=-2.52, p<.05)$. The participants' general self-efficacy pre-test scores is lower than their post-test, follow-up 1 and follow-up 2 scores. The effect size of this existing difference is large $r=0.89 ; 95 \%$ CI $[.49, .98]$.

It is seen that the difference between the participants' FS pre-test scores and post-test, followup 1 and follow-up 2 scores is statistically significant $(z=-2.52, p<.05)$. The participants' psychological well-being pre-test scores are lower than their post-test, follow-up 1 and followup 2 scores. The effect size of this existing difference is large $\mathrm{r}=0.89 ; 95 \%$ CI $[.49, .98]$. According to the results obtained, the hypotheses of the research are accepted.

Table 5. RCI results for clinical significance of difference between scores from LSAS.

\begin{tabular}{|c|c|c|c|c|c|c|c|c|c|c|c|c|}
\hline$P$ & $X_{\text {pretert }}$ & $S D_{\text {pre-etest }}$ & $X_{\text {post-est }}$ & $X_{\text {follow:wl }}$ & $X_{\text {follow:-12 } 2}$ & $X_{\text {post test preteret }}$ & $X_{\text {followiplpl-pre-est }}$ & $X_{\text {follow-1p2-pro-est }}$ & $r_{x}$ & $R C I_{\text {posst-est }}$ & $R I_{\text {follow-wl }}$ & $R C I_{\text {follow-1p } 2}$ \\
\hline P1 & 101 & \multirow{8}{*}{12.13} & 43 & 41 & 37 & -58 & -60 & -64 & \multirow{8}{*}{$.97^{*}$} & -19.52 & -20.19 & -21.54 \\
\hline P2 & 112 & & 84 & 52 & 51 & -28 & -60 & -61 & & -9.42 & -20.19 & -20.53 \\
\hline P3 & 126 & & 34 & 41 & 43 & -92 & -85 & -83 & & -30.96 & -28.60 & -27.93 \\
\hline P4 & 96 & & 44 & 42 & 38 & -52 & -54 & -58 & & -17.50 & -18.17 & -19.52 \\
\hline P5 & 114 & & 66 & 40 & 31 & -48 & -74 & -83 & & -16.15 & -24.90 & -27.93 \\
\hline P6 & 109 & & 34 & 31 & 27 & -75 & -78 & -82 & & -25.24 & -26.25 & -27.59 \\
\hline P7 & 89 & & 27 & 26 & 56 & -62 & -63 & -33 & & -20.86 & -21.20 & -11.10 \\
\hline P8 & 118 & & 33 & 30 & 26 & -85 & -88 & -92 & & -28.60 & -29.61 & -30.96 \\
\hline
\end{tabular}

Note. $P$ : Participant; $r_{x}$ : LSAS reliability co-efficient;

${ }^{*}$ The reliability co-efficient of LSAS is taken from Soykan et al.'s (2003) research. 
When Table 5 is examined, it is seen that the social anxiety scores of all the participants in the post-test, follow-up 1 and follow-up 2 tests are equal to or below the cut-off score. When RCI scores from Table 5 is examined, it is seen that RCI scores of all the participants exceed \pm 1.96 . This finding shows that there is a statistically reliable change in social anxiety when the changes between the scores of the participants from LSAS from the pre-test to the follow-up 2 are evaluated.

Consequently, the changes in all participants' social anxiety post-test, follow-up 1 and followup 2 test scores are clinically significant because they meet the cut-off score and RCI conditions together. The change in the participants' social anxiety is seen in recovered category.

Table 6. RCI results for clinical significance of difference between scores from GSES.

\begin{tabular}{|c|c|c|c|c|c|c|c|c|c|c|c|c|}
\hline$P$ & $X_{\text {pretest }}$ & $S D_{\text {preteres }}$ & $X_{\text {post-lest }}$ & $X_{\text {follow wipl }}$ & $X_{\text {follow:up } 2}$ & $X_{\text {post tete-protect }}$ & $X_{\text {follow-upp-pre-est }}$ & $X_{\text {follow-up2-pre-test }}$ & $r_{x}$ & $R C I_{\text {posit-est }}$ & $R I_{\text {follow-up }}$ & $R C I_{\text {follow-up } 2}$ \\
\hline P1 & 18 & \multirow{8}{*}{4.1} & 26 & 27 & 32 & 8 & 9 & 14 & \multirow{8}{*}{$.80^{*}$} & 3.08 & 3.47 & 5.39 \\
\hline $\mathrm{P} 2$ & 18 & & 29 & 34 & 33 & 11 & 16 & 15 & & 4.24 & 6.17 & 5.78 \\
\hline P3 & 25 & & 36 & 32 & 30 & 11 & 7 & 5 & & 4.24 & 2.70 & 1.92 \\
\hline P4 & 23 & & 34 & 31 & 32 & 11 & 8 & 9 & & 4.24 & 3.08 & 3.47 \\
\hline P5 & 17 & & 30 & 26 & 29 & 13 & 9 & 12 & & 5.01 & 3.47 & 4.62 \\
\hline P6 & 15 & & 38 & 35 & 35 & 23 & 2 & 20 & & 8.87 & 7.71 & 7.71 \\
\hline P7 & 13 & & 33 & 31 & 19 & 20 & 18 & 6 & & 7.71 & 6.94 & 2.31 \\
\hline P8 & 15 & & 39 & 37 & 37 & 24 & 22 & 22 & & 9.25 & 8.48 & 8.48 \\
\hline
\end{tabular}

Note. P: Participant; $r_{x}$ : GSES reliability co-efficient;

*The reliability co-efficient of GSES is taken from Aypay's (2010) research.

When Table 6 is examined, it is seen that the general self-efficacy scores of all the participants in the post-test, follow-up 1 and follow-up 2 tests (except for P7) are equal to or above the cutoff score. Only the P7 follow-up 2 test scored below the cut-off point. When the RCI scores in Table 6 are examined, it is seen that the changes in the post-test and follow-up 1 tests of all participants are clinically significant. In follow-up 2 test, the changes in the general selfefficacy of participants other than P3 and P7 are clinically significant.

Consequently, the changes in the general self-efficacy post-test and follow-up 1 tests of all participants are clinically significant. The changes observed are seen in the recovered category. In the follow-up 2 test, the changes in the general self-efficacy of the participants except for P3 and P7 were clinically significant and seen in the recovered category. In the follow-up 2 test, the change in P3 does not meet the RCI condition and the change in P7 does not meet the cutoff score condition, hence it is not clinically significant. In other words, although the change in the P3 general self-efficacy exceeds the cut-off score in the follow-up 2 test, it is not statistically reliable. Nonetheless, the change in P7 in the follow-up 2 test is statistically reliable but the change is included in the improved category because it does not exceed the cut-off score.

When Table 7 is examined, it is seen that the psychological well-being scores of the majority of the participants in the post-test, follow-up 1 and follow-up 2 tests are equal to or above the cut-off score. P1 and P5 among the participants got a score below the cut-off score in the posttest, and P7 got a score below the cut-off in the follow-up 2 test. When the RCI scores in Table 7 are examined, it is seen that the RCI scores of the participants other than P3 in the post-test, follow-up 1 and follow-up 2 exceed $\mp 1.96$. RCI scores of Participant 3 did not exceed $\mp 1.96$ in any of the three measurements. 
Table 7. RCI results for clinical significance of difference between scores from FS.

\begin{tabular}{|c|c|c|c|c|c|c|c|c|c|c|c|c|}
\hline$P$ & $X_{\text {pre-test }}$ & $S D_{\text {pre-tert }}$ & $X_{\text {post-lest }}$ & $X_{\text {follow-upl }}$ & $X_{\text {follow-up } 2}$ & $X_{\text {positeres-pretert }}$ & $X_{\text {follow-upl-pre-tert }}$ & $X_{\text {follow-1p2 } 2 \text {-pre-eter }}$ & $r_{x}$ & $R C I_{\text {post-est }}$ & $R C I_{\text {follow-yl }}$ & $R C I_{\text {follow:up } 2}$ \\
\hline P1 & 28 & \multirow{8}{*}{9.33} & 42 & 50 & 51 & 14 & 22 & 23 & \multirow{8}{*}{$.86^{*}$} & 2.83 & 4.45 & 4.65 \\
\hline $\mathrm{P} 2$ & 31 & & 45 & 46 & 48 & 14 & 15 & 17 & & 2.83 & 3.03 & 3.44 \\
\hline P3 & 39 & & 47 & 45 & 44 & 8 & 6 & 5 & & 1.62 & 1.21 & 1.01 \\
\hline P4 & 27 & & 44 & 44 & 45 & 17 & 17 & 18 & & 3.44 & 3.44 & 3.64 \\
\hline P5 & 20 & & 42 & 43 & 47 & 22 & 23 & 27 & & 4.45 & 4.65 & 5.46 \\
\hline P6 & 12 & & 53 & 51 & 51 & 41 & 39 & 39 & & 8.30 & 7.90 & 7.90 \\
\hline P7 & 12 & & 49 & 47 & 30 & 37 & 35 & 18 & & 7.49 & 7.08 & 3.64 \\
\hline P8 & 27 & & 52 & 53 & 53 & 25 & 26 & 26 & & 5.06 & 5.26 & 5.26 \\
\hline
\end{tabular}

Note. P: Participant; $r_{x}$ : FS reliability co-efficient;

*FS reliability co-efficient is taken from Telef's (2013) research.

Consequently, the changes in the psychological well-being post-test, follow-up 1 and followup 2 tests of P2, P4, P6 and P8 are clinically significant. The changes observed are seen in the recovered category. The change in P3's psychological well-being is clinically insignificant because it does not meet the RCI condition in any of the three measurements. In other words, although the change in the P3's psychological well-being exceeds the cut-off score in all three measurements, it is not statistically reliable. Additionally, the changes in the psychological well-being of P1 and P5 in the post-test, and of P7 in the follow-up 2 test met the RCI condition but did not meet the cut-off score condition. Hence, the changes observed in these participants are statistically reliable but since they do not exceed the cut-off score, they are included in the improved category.

\section{DISCUSSION and CONCLUSION}

In this study, the effect of iCBT, which includes a specific memory of early negative life experiences and updating related images using the empty chair technique, on social anxiety was researched. The social anxiety post-test scores of the participants decreased statistically significantly compared to the pre-test scores. The decrease continued in the follow-up measurements. In accordance with this, iCBT is effective and has permanent effect. The results gathered are consistent with experimental studies using iCBT with socially anxious university students (Shorey \& Stuart, 2012; Tsitsas \& Paschali, 2014) and participants from different age groups (Datta \& Das, 2016; Goldin et al., 2013; Goldin et al., 2012; Leigh \& Clark, 2016; Narr \& Teachman, 2017; Pinjarkar et al., 2015; Priyamvada et al., 2009; Weiss et al., 2011; Wootton et al., 2018; Yoshinaga, Kobori, et al., 2013; Yoshinaga, Ohshima, et al., 2013). In addition, the study of Leigh and Clark (2016), which includes interventions for early negative life experiences just like current study, is important in that respect. Meta-analysis and review studies, similar to the results of this research, reveal that iCBT is effective in coping with social anxiety (Gil et al., 2001; Mayo-Wilson et al., 2014; Taylor, 1996).

In this study, cognitive and behavioral techniques were used in social anxiety intervention processes. Additionally, participants' negative childhood experiences, the meaning they attributed to these experiences and their images were re-evaluated using the empty chair technique. It could be said that research findings which interfere with the early negative life experiences of individuals with social anxiety via imagery rescripting technique support this study (Frets et al., 2014; Knutsson et al., 2020; Lee \& Kwon, 2013; Nilsson et al., 2012; Norton \& Abbott, 2016; Reimer \& Moscovitch, 2015; Wild et al., 2007, 2008). These studies have 
proven that re-evaluating negative experiences even for a single session is effective in reducing social anxiety, changing the meaning of negative experiences with the effect of images, and weakening negative core beliefs. It is also seen that this effect continues in the follow-up measurements as well. Wild and Clark (2011) emphasize that images that are associated with a specific memory of early negative life experiences have an important role in the maintenance of social anxiety. They explain that these images have to be intervened in order to cope with social anxiety. In this study, it can be stated that re-evaluating the participants' a specific memory of early negative life experiences and related images with the empty chair technique is effective in reducing their anxiety.

The decrease in all participants' social anxiety is clinically significant and can be seen in recovered category. These results appear to be consistent with the study results in which clinical significance is calculated (Bogels et al., 2014; Clark et al., 2006; Goldin et al., 2013; Mörtberg et al., 2007; Shorey \& Stuart, 2012; Stangier et al., 2003; Wootton et al., 2018). The fact that the study was conducted with a group that was not clinically diagnosed may have facilitated the participants' effective benefiting and recovery from an intervention process that lasted for a total of 12 weeks. Different from the studies above, in this study, a specific memory of early negative life experiences and images of the participants were re-evaluated experientially using the empty chair technique. This might be another reason why the participants benefited from this process. To sum, the results gathered with regards to the clinical significance of the decrease in the participants' social anxiety present a crucial proof that show the intervention is effective. Additionally, the fact that the effect obtained continues to increase in both follow-up measurements supports that the effect of the study is permanent.

iCBT applied in this study is also effective in the increase of the participants' general selfefficacy. This result from the study is consistent with the experimental studies where iCBT is used (Jafari et al., 2012; Keshi \& Basavarajappa, 2013). Jafari et al. in particular (2012) comes to be conclusion that iCBT is effective in the increasing of general self-efficacy and that the effect continues in the follow-up measurement. Another resemblance between these studies and current study is that the participants were selected from a non-clinical sample. This may be one of the factors in increasing general self-efficacy as a result of the intervention. Additionally, it can be said that in this study the interventions for early negative life experiences and images have an effect on the increase in the general self-efficacy of the participants.

The increase observed in the general self-efficacy post-test and follow-up 1 test of all participants are clinically significant. These increases can be seen in the recovered category. In the follow-up 2 test, the increase in two participants was not clinically significant. Although the change in one of these participants (P7) was statistically reliable, it was not clinically significant. For this reason, the change in their general self-efficacy is included in the improved category. When this participant was contacted for the follow-up 2 test, they stated that they had "serious family problems". It can be said that this situation had an impact on the change observed in the follow-up 2 test. The results obtained show that applied iCBT has a clinically significant effect on increasing general self-efficacy. Also, follow-up measurements collected support that this effect is permanent. In the literature review, no study was found in which clinical significance of general self-efficacy was reported. It is thought that this result about general self-efficacy is original, and will contribute to the literature.

It is seen that the iCBT applied in this study is effective in the increase of the participants' psychological well-being as well. This result is consistent with the research results in the literature. Studies show that CBT and approaches based on CBT increase the psychological well-being (Fava et al., 1998; Freeman et al., 2014; Ruini et al., 2006). In a meta-analysis study, it is emphasized that face-to-face applications in which behavioral interventions were used were effective in increasing psychological well-being (Weiss et al., 2016). Similarly, in this study 
too, it was found that iCBT decreases social anxiety while it also increases psychological wellbeing. In addition, there are studies in the literature showing that early negative life experiences have negative effects on well-being (Melkman, 2017; Mosley-Johnson et al., 2018). In Ryff's (2014) model, these results are seen to be related to the self-acceptance dimension, which includes the individual's positive feelings and evaluations about their past life and themselves. In other words, early negative life experiences create an obstacle in people's self-acceptance and affect their psychological well-being. In this study, it can be said that the interventions made for a specific memory of early negative life experiences and images of the participants have an effect on increasing their psychological well-being.

It was seen that the increase in the psychological well-being of half of the participants is clinically significant. These increases can be seen in the recovered category. In the follow-up test measurements, the number of participants whose change in their psychological well-being is clinically significant increased. And this shows that the effect of the iCBT applied continues to increase. The change in psychological well-being of only one participant (P3) was not clinically significant in all three measurements. In the post-test, the change in two participants (P1 and P5) was clinically insignificant. Although the psychological well-being of these participants increased compared to their pre-test scores, the change in post-test measurements was not clinically significant since the score was one point below the cut-off score. However, the psychological well-being of both participants increased in the follow-up measurements and became clinically significant. In the follow-up 2 test, on the other hand, the change in one participant (P7) was not clinically significant, as it did not exceed the cut-off score. It can be said that the follow-up 2 measurement of this participant when they were experiencing "serious family problems" had an effect on their psychological well-being as well as their general selfefficacy. According to the results obtained, iCBT applied has a clinically significant effect on increasing the psychological well-being of the participants. Also, follow-up measurements collected support that this effect continues to increase. In the literature review, no study was found in which clinical significance of psychological well-being was reported. It is thought that this result about psychological well-being is original and will contribute to the literature.

The changes observed in the post-test and follow-up 1 and 2 measurements of social anxiety, general self-efficacy, and psychological well-being in this study have a large effect size. These results are consistent with many studies in which CBT was used in relation to social anxiety (Clark et al., 2006; Clark et al., 2003; Gaudiano \& Herbert, 2003; Mayo-Wilson et al., 2014; Mörtberg et al., 2007; Stangier et al., 2003; Wootton et al., 2018; Yoshinaga, Ohshima, et al., 2013). Post-test results regarding general self-efficacy are similar to the study by Keshi and Basavarajappa (2013) in which they used iCBT to increase general self-efficacy. Post-test results on psychological well-being are consistent with the study of Freeman et al. (2014), while they are different from the findings of Weiss et al. (2016). In the meta-analysis study of Weiss et al. (2016), it was seen that the post-test effect sizes were medium and small as well as large. The most important reason for this may be the inclusion of studies involving different theoretical approaches and participants with different characteristics (selected from clinical and non-clinical samples) in the meta-analysis.

This study shows that the applied iCBT is effective in reducing the social anxiety of university students in terms of statistical, clinical significance and effect size. It has been determined that the effect of the study continues to increase in the follow-up measurements taken. These results contribute to research results revealing the impact of early negative life experiences and images on coping with social anxiety (e.g., Hackmann et al., 2000; Wild \& Clark, 2011; Wild et al., 2007, 2008). In addition, it was revealed that the iCBT applied contributed to the decrease in the social anxiety of the participants, while also contributing to the increase in their general self-efficacy and psychological well-being. This provides further evidence that the applied counseling process is effective. 
The effectiveness of the iCBT applied in this study can be re-tested with applications that will involve more socially anxious university students in the future. By making necessary updates on the configured iCBT, its effectiveness can be investigated in different age groups or people with different problems accompanying social anxiety as well. Additionally, the applications on the non-clinical sample in this study can be tested on clinical samples in terms of its effectiveness in the future. It was not possible to form a control group as a limited number of socially anxious participants were reached in this study. In future studies, the effectiveness of this study can be researched once again with participants that include a control group. In new applications that will be made, the effectiveness of the sessions and the structured psychological counselor can be investigated in different dimensions by taking measurements after each session. In this way, the progress the participants make and in which sessions can be determined.

\section{Acknowledgments}

This study is based on a summary of the doctoral dissertation entitled "The Effect of Individual Counseling Based on Cognitive Behavior Therapy on Social Anxiety, Self-Efficacy, and Psychological Well-Being" prepared in the Guidance and Psychological Counseling Program, Ankara University.

\section{Availability of Data}

Data are openly available at the research Open Science Framework page (https://osf.io/5kbr7/).

\section{Declaration of Conflicting Interests and Ethics}

The authors have no competing interests to declare that are relevant to the content of this article. All scientific responsibility of the manuscript belongs to the authors. This study was approved by the Blinded University Ethics Committee, under the code of 85434274-050.04.04/6260.

\section{Authorship Contribution Statement}

Volkan Avsar: Investigation, Visualization, Structuring and application of the iCBT process, Participants' recruitment, Drafting manuscript. Seher A. Sevim: Methodology and Supervision.

\section{Orcid}

Volkan Avsar (iD https://orcid.org/0000-0001-9427-9425

Seher A. Sevim (D) https://orcid.org/0000-0002-4914-2486

\section{REFERENCES}

Aderka, I.M., Hofmann, S.G., Nickerson, A., Hermesh, H., Gilboa-Schechtman, E., \& Marom, S. (2012). Functional impairment in social anxiety disorder. Journal of Anxiety Disorders, 26(3), 393-400. https://doi.org/10.1016/j.janxdis.2012.01.003

American Psychiatric Association. (2013). Diagnostic and statistical manual of mental disorders (5th ed.). https://doi.org/10.1176/appi.books.9780890425596

Arnkoff, D.B. (1981). Flexibility in practicing cognitive therapy. In G. Emery, S.D. Hollon, \& R.C. Bedrosian (Eds.), New directions in cognitive therapy (1st ed., pp. 203-223). The Guilford Press.

Arntz, A. (2011). Imagery rescripting for personality disorders. Cognitive and Behavioral Practice, 18(4), 466-481. https://doi.org/10.1016/j.cbpra.2011.04.006

Atkins, D.C., Bedics, J.D., McGlinchey, J.B., \& Beauchaine, T.P. (2005). Assessing clinical significance: Does it matter which method we use? Journal of Consulting and Clinical Psychology, 73(5), 982-989. https://doi.org/10.1037/0022-006x.73.5.982

Aypay, A. (2010). Genel özyeterlik ölçeği'nin (GÖYÖ) Türkçe'ye uyarlama çalışması [The adaptation study of general self-efficacy (GSE) scale to Turkish]. Inönü Üniversitesi 
Ĕ̈itim Fakültesi Dergisi, 11(2), 113-131. https://dergipark.org.tr/tr/download/articlefile/92265

Bandura, A. (1977a). Self-efficacy: Toward a unifying theory of behavioral change. Psychological Review, 84(2), 191-215. https://doi.org/10.1016/0146-6402(78)90002-4

Bandura, A. (1977b). Social learning theory (1st ed.). Prentice Hall.

Bandura, A. (1997). Self-efficacy: The exercise of control (1st ed.). W: H. Freeman \& Company.

Baptista, C.A., Loureiro, S.R., Osorio, F.D., Zuardi, A.W., Magalhaes, P.V., Kapczinski, F., Santos, A., Freitas-Ferrari, M.C., \& Crippa, J.A.S. (2012). Social phobia in Brazilian university students: Prevalence, under-recognition and academic impairment in women. Journal of Affective Disorders, 136(3), 857-861. https://doi.org/10.1016/j.jad.2011.09.0 $\underline{22}$

Bauer, S., Lambert, M.J., \& Nielsen, S.L. (2004). Clinical significance methods: A comparison of statistical techniques. Journal of Personality Assessment, 82(1), 60-70. https://doi.org/10.1207/s15327752jpa8201 11

Binelli, C., Ortiz, A., Muñiz, A., Gelabert, E., Ferraz, L., Filho, A.S., Crippa, J.A.S., Nardi, A. E., Subira, S., \& Martin-Santos, R. (2012). Social anxiety and negative early life events in university students. Revista Brasileira De Psiquiatria, 34(1), 69-74. https://doi.org/10.1590/s1516-44462012000500006

Biran, M., \& Wilson, G.T. (1981). Treatment of phobic disorders using cognitive and exposure methods: A self-efficacy analysis. Journal of Consulting and Clinical Psychology, 49(6), 886-899. https://doi.org/10.1037/0022-006x.49.6.886

Bogels, S.M., Wijts, P., Oort, F.J., \& Sallaerts, S.J.M. (2014). Psychodynamic psychotherapy persus cognitive behavior therapy for social anxiety disorder: An efficacy and partial effectiveness trial. Depression and Anxiety, 31(5), 363-373. https://doi.org/10.1002/da.2 $\underline{2246}$

Brook, C.A., \& Willoughby, T. (2015). The social ties that bind: Social anxiety and academic achievement across the university years. Journal of Youth and Adolescence, 44(5), 11391152. https://doi.org/10.1007/s10964-015-0262-8

Clark, D.M. (2001). A cognitive perspective on social phobia. In W. R. Crozier \& L. E. Alden (Eds.), International handbook of social anxiety: Concepts, research and interventions relating to the self and shyness (1st ed., pp. 405-430). John Wiley \& Sons Ltd.

Clark, D.M., Ehlers, A., Hackmann, A., McManus, F., Fennell, M., Grey, N., Waddington, L., \& Wild, J. (2006). Cognitive therapy versus exposure and applied relaxation in social phobia: A randomized controlled trial. Journal of Consulting and Clinical Psychology, 74(3), 568-578. https://doi.org/10.1037/0022-006x.74.3.568

Clark, D.M., Ehlers, A., McManus, F., Hackmann, A., Fennell, M., Campbell, H., Flower, T., Davenport, C., \& Louis, B. (2003). Cognitive therapy versus fluoxetine in generalized social phobia: A randomized placebo-controlled trial. Journal of Consulting and Clinical Psychology, 71(6), 1058-1067. https://doi.org/10.1037/0022-006x.71.6.1058

Clark, D.M., \& Wells, A. (1995). A cognitive model of social phobia. In R. G. Heimberg, M. R. Liebowitz, D.A. Hope, \& F.R. Schneier (Eds.), Social phobia: Diagnosis, assessment and treatment (1st ed., pp. 69-93). The Guilford Press.

Datta, S., \& Das, S. (2016). Cognitive behaviour therapy in social phobia: A case study. SIS Journal of Projective Psychology \& Mental Health, 23(3), 88-95.

Diener, E., Wirtz, D., Tov, W., Kim-Prieto, C., Choi, D.W., Oishi, S., \& Biswas-Diener, R. (2010). New well-being measures: Short scales to assess flourishing and positive and negative feelings. Social Indicators Research, 97(2), 143-156. https://doi.org/10.1007/s 11205-009-9493-y 
Faravelli, C., Zucchi, T., Viviani, B., Salmoria, R., Perone, A., Paionni, A., Scarpato, A., Vigliaturo, D., Rosi, S., D'adamo, D., Bartolozzi, D., Cecchi, C., \& Abrardi, L. (2000). Epidemiology of social phobia: A clinical approach. European Psychiatry, 15(1), 17-24. https://doi.org/10.1016/S0924-9338(00)00215-7

Fava, G.A., Rafanelli, C., Cazzaro, M., Conti, S., \& Grandi, S. (1998). Well-being therapy. A novel psychotherapeutic approach for residual symptoms of affective disorders. Psychological Medicine, 28(2), 475-480. https://doi.org/10.1017/S0033291797006363

Fehm, L., Beesdo, K., Jacobi, F., \& Fiedler, A. (2008). Social anxiety disorder above and below the diagnostic threshold: prevalence, comorbidity and impairment in the general population. Social Psychiatry and Psychiatric Epidemiology, 43(4), 257-265. https://doi.org/10.1007/s00127-007-0299-4

Freeman, D., Pugh, K., Dunn, G., Evans, N., Sheaves, B., Waite, F., Černis, E.R.L., \& Fowler, D. (2014). An early phase II randomised controlled trial testing the effect on persecutory delusions of using CBT to reduce negative cognitions about the self: The potential benefits of enhancing self confidence. Schizophrenia Research, 160(1-3), 186-192 https://doi.org/10.1016/j.schres.2014.10.038

Frets, P.G., Kevenaar, C., \& van der Heiden, C. (2014). Imagery rescripting as a stand-alone treatment for patients with social phobia: A case series. Journal of Behavior Therapy and Experimental Psychiatry, 45(1), 160-169. https://doi.org/10.1016/j.jbtep.2013.09.00 $\underline{6}$

Gaudiano, B.A., \& Herbert, J.D. (2003). Preliminary psychometric evaluation of a new selfefficacy scale and its relationship to treatment outcome in social anxiety disorder. Cognitive Therapy and Research, 27(5), 537-555. https://doi.org/10.1023/A:102635500 $\underline{4548}$

Ghaedi, G., Tavoli, A., Bakhtiari, M., Melyani, M., \& Sahragard, M. (2010). Quality of life in college students with and without social phobia. Social Indicators Research, 97(2), 247256. https://doi.org/10.1007/s11205-009-9500-3

Gil, P.J.M., Carrillo, F.X.M., \& Meca, J.S. (2001). Effectiveness of cognitive-behavioural treatment in social phobia: A meta-analytic review. Psychology in Spain, 5(1), 17-25.

Goldin, P.R., Ziv, M., Jazaieri, H., Hahn, K., Heimberg, R., \& Gross, J.J. (2013). Impact of cognitive behavioral therapy for social anxiety disorder on the neural dynamics of cognitive reappraisal of negative self-beliefs: Randomized clinical trial. Jama Psychiatry, 70(10), 1048-1056. https://doi.org/10.1001/jamapsychiatry.2013.234

Goldin, P.R., Ziv, M., Jazaieri, H., Werner, K., Kraemer, H., Heimberg, R.G., \& Gross, J.J. (2012). Cognitive reappraisal self-efficacy mediates the effects of individual cognitivebehavioral therapy for social anxiety disorder. Journal of Consulting and Clinical Psychology, 80(6), 1034-1040. https://doi.org/10.1037/a0028555

Gordon, D., Wong, J., \& Heimberg, R.G. (2014). Cognitive-behavioral therapy for social anxiety disorder: The state of the science. In J.W. Weeks (Ed.), The wiley blackwell handbook of social anxiety disorder (1st ed., pp. 477-497). John Wiley \& Sons.

Greenberg, L.S. (2010). Emotion-focused therapy: A clinical synthesis. The Journal of Lifelong Learning in Psychiatry, 81(1), 32-42. https://doi.org/10.1176/foc.8.1.foc32

Gultekin, B.K., \& Dereboy, I.F. (2011). Üniversite öğrencilerinde sosyal fobinin yaygınlığı ve sosyal fobinin yaşam kalitesi, akademik başarı ve kimlik oluşumu üzerine etkileri [The prevalence of social phobia, and its impact on quality of life, academic achievement, and identity formation in university students]. Turk Psikiyatri Dergisi, 22(3), 150-158. https://www.turkpsikiyatri.com/PDF/C22S3/150-158

Hackmann, A., Clark, D.M., \& McManus, F. (2000). Recurrent images and early memories in social phobia. Behaviour Research and Therapy, 38(6), 601-610. https://doi.org/10.101 $\underline{\text { 6/S0005-7967(99)00161-8 }}$ 
Hackmann, A., Surawy, C., \& Clark, D.M. (1998). Seeing yourself through others' eyes: A study of spontaneously occurring images in social phobia. Behavioural and Cognitive Psychotherapy, 26, 3-12. https://doi.org/10.1017/S1352465898000022

Harwood, T.M., Beutler, L.E., \& Charvat, M. (2010). Cognitive-behavioral therapy and psychotherapy integration. In K. S. Dobson (Ed.), Handbook of cognitive-behavioral therapies (3rd ed., pp. 94-130). The Guilford Press.

Hirsch, C., Meynen, T., \& Clark, D. (2004). Negative self-imagery in social anxiety contaminates social interactions. Memory, 12(4), 496 506. https://doi.org/10.1080/0965 $\underline{8210444000106}$

Hirsch, C.R., Clark, D.M., Mathews, A., \& Williams, R. (2003). Self-images play a causal role in social phobia. Behaviour Research and Therapy, 41(8), 909-921. https://doi.org/10.1 016/S0005-7967(02)00103-1

Hirsch, C.R., Mathews, A., Clark, D.M., Williams, R., \& Morrison, J.A. (2006). The causal role of negative imagery in social anxiety: A test in confident public speakers. Journal of Behavior Therapy and Experimental Psychiatry, 37(2), 159-170. https://doi.org/10.1016 /j.jbtep.2005.03.003

Holaway, R.M., \& Heimberg, R.G. (2004). Cognitive-behavioral therapy for social anxiety disorder: A treatment review. In B. Bandelow \& D.J. Stein (Eds.), Social anxiety disorder (1st ed., pp. 207-220).

Howes, J.L., \& Parrott, C.A. (1991). Conceptualization and flexibility in cognitive therapy. In T.M. Vallis, J.L. Howes, \& P.C. Miller (Eds.), The challenge of cognitive therapy: Applications to nontraditional populations (pp. 25-42). Springer.

Huppert, F.A. (2009). Psychological well-being: Evidence regarding its causes and consequences. Applied Psychology: Health and Well Being, 1(2), 137-164. https://doi.org/10.1111/j.1758-0854.2009.01008.x

Izgic, F., Akyuz, G., Dogan, O., \& Kugu, N. (2004). Social phobia among university students and its relation to self-esteem and body image. The Canadian Journal of Psychiatry, 49(9), 630-634. https://doi.org/10.1177/070674370404900910

Jacobson, N.S., Follette, W.C., \& Revenstorf, D. (1984). Psychotherapy outcome research: Methods for reporting variability and evaluating clinical significance. Behavior Therapy, 15(4), 336-352. https://doi.org/10.1016/S0005-7894(84)80002-7

Jacobson, N.S., \& Truax, P. (1991). Clinical significance: A statistical approach to defining meaningful change in psychotherapy research. Journal of Consulting and Clinical Psychology, 59(1), 12-19. https://doi.org/10.1037/0022-006x.59.1.12

Jafari, M., Shahidi, S., \& Abedin, A. (2012). Comparing the effectiveness of cognitive behavioral therapy and stages of change model on improving abstinence self-efficacy in Iranian substance dependent adolescents. Iranian Journal of Psychiatry and Behavioral Sciences, 6(2), 7-15.

Kashdan, T.B., Julian, T., Merritt, K., \& Uswatte, G. (2006). Social anxiety and posttraumatic stress in combat veterans: Relations to well-being and character strengths. Behaviour Research and Therapy, 44(4), 561-583. https://doi.org/10.1016/j.brat.2005.03.010

Kellogg, S. (2004). Dialogical encounters: Contemporary perspectives on "chairwork" in psychotherapy. Psychotherapy: Theory, Research, Practice, Training, 41(3), 310-320. https://doi.org/10.1037/0033-3204.41.3.310

Keshi, A.K., \& Basavarajappa. (2013). Effectiveness of cognitive behavior therapy on selfefficacy among high school students. Asian Journal of Management Sciences \& Education, 2(4), 68-79.

Kessler, R.C., Petukhova, M., Sampson, N.A., Zaslavsky, A.M., \& Wittchen, H.U. (2012). Twelve-month and lifetime prevalence and lifetime morbid risk of anxiety and mood 
disorders in the United States. International Journal of Methods in Psychiatric Research, 21(3), 169-184. https://doi.org/10.1002/mpr.1359

Knutsson, J., Nilsson, J.E., Eriksson, Å., \& Järild, L. (2020). Imagery rescripting and exposure in social anxiety: A randomized trial comparing treatment techniques. Journal of Contemporary Psychotherapy, 50(3), 233-240. https://doi.org/10.1007/s10879-019$\underline{09448-1}$

Krans, J., de Bree, J., \& Bryant, R.A. (2014). Autobiographical memory bias in social anxiety. Memory, 22(8), 890-897. https://doi.org/10.1080/09658211.2013.844261

Kring, A.M., \& Johnson, S.L. (2014). Abnormal Psychology (12th ed.). John Wiley \& Sons, Inc.

Kuo, J.R., Goldin, P.R., Werner, K., Heimberg, R.G., \& Gross, J.J. (2011). Childhood trauma and current psychological functioning in adults with social anxiety disorder. Journal of Anxiety Disorders, 25(4), 467-473. https://doi.org/10.1016/j.janxdis.2010.11.011

Lee, S.W., \& Kwon, J.H. (2013). The efficacy of imagery rescripting (IR) for social phobia: A randomized controlled trial. Journal of Behavior Therapy and Experimental Psychiatry, 44(4), 351-360. https://doi.org/10.1016/j.jbtep.2013.03.001

Leigh, E., \& Clark, D.M. (2016). Cognitive therapy for social anxiety disorder in adolescents: A development case series. Behavioural and Cognitive Psychotherapy, 44(1), 1-17. https://doi.org/10.1017/S1352465815000715

Liebowitz, M.R. (1987). Social phobia. Modern Problems of Pharmacopsychiatry, 22, 141173. https://doi.org/10.1159/000414022

Luszczynska, A., Gutierrez-Dona, B., \& Schwarzer, R. (2005). General self-efficacy in various domains of human functioning: Evidence from five countries. International Journal of Psychology, 40(2), 80-89. https://doi.org/10.1080/00207590444000041

Magee, W.J. (1999). Effects of negative life experiences on phobia onset. Social Psychiatry and Psychiatric Epidemiology, 34(7), 343-351. https://doi.org/10.1007/s001270050154

Makkar, S.R., \& Grisham, J.R. (2011). Social anxiety and the effects of negative self-imagery on emotion, cognition, and post-event processing. Behaviour Research and Therapy, 49(10), 654-664. https://doi.org/10.1016/j.brat.2011.07.004

Maner, J.K., \& Kenrick, D.T. (2010). When adaptations go awry: Functional and dysfunctional aspects of social anxiety. Social Issues and Policy Review, 4(1), 111-142. https://doi.org/10.1111/j.1751-2409.2010.01019.x

Mayo-Wilson, E., Dias, S., Mavranezouli, I., Kew, K., Clark, D.M., Ades, A.E., \& Pilling, S. (2014). Psychological and pharmacological interventions for social anxiety disorder in adults: A systematic review and network meta-analysis. The Lancet Psychiatry, 1(5), 368376. https://doi.org/10.1016/S2215-0366(14)70329-3

McManus, F., Sacadura, C., \& Clark, D.M. (2008). Why social anxiety persists: An experimental investigation of the role of safety behaviours as a maintaining factor. Journal of Behavior Therapy and Experimental Psychiatry, 39(2), 147-161. https://doi.org/10.1016/j.jbtep.2006.12.002

Melkman, E.P. (2017). Childhood adversity, social support networks and well-being among youth aging out of care: An exploratory study of mediation. Child Abuse \& Neglect, 72, 85-97. https://doi.org/10.1016/j.chiabu.2017.07.020

Mellings, T.M.B., \& Alden, L.E. (2000). Cognitive processes in social anxiety: The effects of self-focus, rumination and anticipatory processing. Behaviour Research and Therapy, 38(3), 243-257. https://doi.org/10.1016/S0005-7967(99)00040-6

Mosley-Johnson, E., Garacci, E., Wagner, N., Mendez, C., Williams, J.S., \& Egede, L.E. (2018). Assessing the relationship between adverse childhood experiences and life satisfaction, psychological well-being, and social well-being: United States longitudinal 
cohort 1995-2014. Quality of Life Research, Advance online publication. https://doi.org/10.1007/s11136-018-2054-6

Mörtberg, E., Clark, D.M., Sundin, Ö., \& Wistedt, A.Å. (2007). Intensive group cognitive treatment and individual cognitive therapy vs. treatment as usual in social phobia: A randomized controlled trial. Acta Psychiatrica Scandinavica, 115(2), 142-154. https://doi.org/10.1111/j.1600-0447.2006.00839.x

Narr, R.K., \& Teachman, B.A. (2017). Using advances from cognitive behavioral models of anxiety to guide treatment for social anxiety disorder. Journal of Clinical Psychology, 73(5), 524-535. https://doi.org/10.1002/jclp.22450

Nilsson, J.E., Lundh, L.G., \& Viborg, G. (2012). Imagery rescripting of early memories in social anxiety disorder: An experimental study. Behaviour Research and Therapy, 50(6), 387-392. https://doi.org/10.1016/j.brat.2012.03.004

Nordstrom, A.H., Goguen, L.M.S., \& Hiester, M. (2014). The effect of social anxiety and selfesteem on college adjustment, academics, and retention. Journal of College Counseling, 17(1), 48-63. https://doi.org/10.1002/j.2161-1882.2014.00047.x

Norton, A.R., \& Abbott, M.J. (2016). The efficacy of imagery rescripting compared to cognitive restructuring for social anxiety disorder. Journal of Anxiety Disorders, 40, 18-28. https://doi.org/10.1016/j.janxdis.2016.03.009

Norton, A.R., Abbott, M.J., Dobinson, K.A., Pepper, K.L., \& Guastella, A.J. (2021). Rescripting social trauma: A pilot study investigating imagery rescripting as an adjunct to cognitive behaviour therapy for social anxiety disorder. Cognitive Therapy and Research, 45(6), 1180-1192. https://doi.org/10.1007/s10608-021-10221-9

Özbay, Y., \& Palanc1, M. (2001). Sosyal kaygı ölçeği: Geçerlik ve güvenirlik çalışması [Social anxiety scale: The validity and reliability study] VI. Ulusal Psikolojik Danışma ve Rehberlik Kongresi [VI. National Psychological Counseling and Guidance Congress], Ankara, Turkey.

Paivio, S.C., Hall, I.E., Holowaty, K.A.M., Jellis, J.B., \& Tran, N. (2001). Imaginal confrontation for resolving child abuse issues. Psychotherapy Research, 11(4), 433-453. https://doi.org/10.1093/ptr/11.4.433

Pinjarkar, R.G., Sudhir, P.M., \& Math, S.B. (2015). Brief cognitive behavior therapy in patients with social anxiety disorder: A preliminary investigation. Indian Journal of Psychological Medicine, 37(1), 20-25. https://doi.org/10.4103/0253-7176.150808

Priyamvada, R., Kumari, S., Prakash, J., \& Chaudhury, S. (2009). Cognitive behavioral therapy in the treatment of social phobia. Industrial Psychiatry Journal, 18(1), 60-63. https://doi.org/10.4103/0972-6748.57863

Regis, J.M.O., Ramos-Cerqueira, A.T.A., Lima, M.C.P., \& Torres, A.R. (2018). Social anxiety symptoms and body image dissatisfaction in medical students: Prevalence and correlates. Jornal Brasileiro de Psiquiatria, 67, 65-73. https://doi.org/10.1590/0047-20850000001 $\underline{87}$

Reimer, S.G., \& Moscovitch, D.A. (2015). The impact of imagery rescripting on memory appraisals and core beliefs in social anxiety disorder. Behaviour Research and Therapy, 75, 48-59. https://doi.org/10.1016/j.brat.2015.10.007

Romano, M., Moscovitch, D.A., Huppert, J.D., Reimer, S.G., \& Moscovitch, M. (2020). The effects of imagery rescripting on memory outcomes in social anxiety disorder. Journal of Anxiety Disorders, 69. https://doi.org/10.1016/j.janxdis.2019.102169

Rosenthal, R. (1991). Meta-analytic procedures for social research (Revised ed., Vol. 6). Sage Publications.

Rudy, B.M., Davis Ill, T.E., \& Matthews, R.A. (2012). The relationship among self-efficacy, negative self-referent cognitions, and social anxiety in children: A multiple mediator model. Behavior Therapy, 43(3), 619-628. https://doi.org/10.1016/j.beth.2011.11.003 
Ruini, C., Belaise, C., Brombin, C., Caffo, E., \& Fava, G.A. (2006). Well-being therapy in school settings: A pilot study. Psychotherapy and Psychosomatics, 75(6), 331-336. https://doi.org/10.1159/000095438

Ruscio, A.M., Brown, T.A., Chiu, W.T., Sareen, J., Stein, M.B., \& Kessler, R.C. (2008). Social fears and social phobia in the USA: results from the National Comorbidity Survey Replication. Psychological Medicine, 38(1), 15-28. https://doi.org/10.1017/S003 3291707001699

Ryff, C.D. (1989a). Beyond ponce de leon and life satisfaction: New directions in quest of successful ageing. International Journal of Behavioral Development, 12(1), 35-55. https://doi.org/10.1177/016502548901200102

Ryff, C.D. (1989b). Happiness is everything, or is it? Explorations on the meaning of psychological well-being. Journal of Personality and Social Psychology, 57(6), 10691081. https://doi.org/10.1037/0022-3514.57.6.1069

Ryff, C.D. (2014). Psychological well-being revisited: Advances in the science and practice of eudaimonia. Psychotherapy and Psychosomatics, 83(1), 10-28. https://doi.org/10.1159/ $\underline{000353263}$

Scherbaum, C.A., Cohen-Charash, Y., \& Kern, M.J. (2006). Measuring general self-efficacy: A comparison of three measures using item response theory. Educational and Psychological Measurement, 66(6), 1047-1063. https://doi.org/10.1177/0013164406288 $\underline{171}$

Schwarzer, R. (1994). Optimism, vulnerability, and self-beliefs as health-related cognitions: A systematic overview. Psychology and Health, 9(3), 161-180. https://doi.org/10.1080/08 $\underline{870449408407475}$

Schwarzer, R., \& Jerusalem, M. (1995). Generalized self-efficacy scale. In J. Weinman, S.C. Wright, \& M. Johnston (Eds.), Measures in health psychology: A user's portfolio (1st ed., pp. 35-37). NFER-Nelson.

Shorey, R.C., \& Stuart, G.L. (2012). Manualized cognitive-behavioral treatment of social anxiety disorder: A case study. Clinical Case Studies, 11(1), 35-47. https://doi.org/10.11 $77 / 1534650112438462$

Soykan, C., Ozguven, H. D., \& Gencoz, T. (2003). Liebowitz social anxiety scale: The Turkish version. Psychological Reports, 93(3), 1059-1069. https://doi.org/10.2466/Pr0.93.7.105 9-1069

Stangier, U., Heidenreich, T., Peitz, M., Lauterbach, W., \& Clark, D.M. (2003). Cognitive therapy for social phobia: Individual versus group treatment. Behaviour Research and Therapy, 41(9), 991-1007. https://doi.org/10.1016/S0005-7967(02)00176-6

Stopa, L., \& Jenkins, A. (2007). Images of the self in social anxiety: Effects on the retrieval of autobiographical memories. Journal of Behavior Therapy and Experimental Psychiatry, 38(4), 459-473. https://doi.org/10.1016/j.jbtep.2007.08.006

Taylor, S. (1996). Meta-analysis of cognitive-behavioral treatments for social phobia. Journal of Behavior Therapy and Experimental Psychiatry, 27(1), 1-9. https://doi.org/10.1016/0 005-7916(95)00058-5

Telef, B.B. (2013). Psikolojik iyi oluş ölçeği: Türkçeye uyarlama, geçerlik ve güvenirlik çalışması [The Adaptation of psychological well-being into Turkish: A validity and reliability study]. Hacettepe Üniversitesi Ĕ̈itim Fakültesi Dergisi, 28(3), 374-384. https://dergipark.org.tr/tr/download/article-file/87222

Tsitsas, G.D., \& Paschali, A.A. (2014). A Cognitive-behavior therapy applied to a social anxiety disorder and a specific phobia: Case study. Health Psychology Research, 2(1603), 78-82. https://doi.org/10.4081/hpr.2014.1603

Vassilopoulos, S.P. (2012). Social anxiety and memory biases in middle childhood: A preliminary study. Hellenic Journal of Psychology, 9(2), 114-131. 
Wang, J.L., Jackson, L.A., Gaskin, J., \& Wang, H.Z. (2014). The effects of Social Networking Site (SNS) use on college students' friendship and well-being. Computers in Human Behavior, 37, 229-236. https://doi.org/10.1016/j.chb.2014.04.051

Weiss, B.J., Singh, J.S., \& Hope, D.A. (2011). Cognitive-behavioral therapy for immigrants presenting with social anxiety disorder: Two case studies. Clinical Case Studies, 10(4), 324-342. https://doi.org/10.1177/1534650111420706

Weiss, L.A., Westerhof, G.J., \& Bohlmeijer, E.T. (2016). Can we increase psychological wellbeing? The effects of interventions on psychological well-being: A meta-analysis of randomized controlled trials. Plos ONE, 11(6). https://doi.org/10.1371/journal.pone.015 $\underline{8092}$

Wersebe, H., Lieb, R., Meyer, A.H., Miche, M., Mikoteit, T., Imboden, C., Hoyer, J., Bader, K., Hatzinger, M., \& Gloster, A. T. (2018). Well-being in major depression and social phobia with and without comorbidity. International Journal of Clinical and Health Psychology, 18(3), 201-208. https://doi.org/10.1016/j.ijchp.2018.06.004

Wild, J., \& Clark, D.M. (2011). Imagery rescripting of early traumatic memories in social phobia. Cognitive and Behavioral Practice, 18(4), 433-443. https://doi.org/10.1016/j.cb pra.2011.03.002

Wild, J., \& Clark, D.M. (2015). Experiential exercises and imagery rescripting in social anxiety disorder: New perspectives on changing beliefs. In N. C. Thoma \& D. McKay (Eds.), Working with emotion in cognitive-behavioral therapy: Techniques for clinical practice (1st ed., pp. 216-236). The Guilford Press.

Wild, J., Hackmann, A., \& Clark, D.M. (2007). When the present visits the past: Updating traumatic memories in social phobia. Journal of Behavior Therapy and Experimental Psychiatry, 38(4), 386-401. https://doi.org/10.1016/j.jbtep.2007.07.003

Wild, J., Hackmann, A., \& Clark, D.M. (2008). Rescripting early memories linked to negative images in social phobia: A pilot study. Behavior Therapy, 39(1), 47-56. https://doi.org/1 $\underline{0.1016 / \text { j.beth.2007.04.003 }}$

Wootton, B. M., Hunn, A., Moody, A., Lusk, B. R., Ranson, V. A., \& Felmingham, K. L. (2018). Accelerated outpatient individual cognitive behavioural therapy for social anxiety disorder: A preliminary pilot study. Behavioural and Cognitive Psychotherapy, 46(6), 690-705. https://doi.org/10.1017/S1352465818000267

Yoshinaga, N., Kobori, O., Iyo, M., \& Shimizu, E. (2013). Cognitive behaviour therapy using the Clark \& Wells model: A case study of a Japanese social anxiety disorder patient. The Cognitive Behaviour Therapist, 6(3), 1-30. https://doi.org/10.1017/S1754470X1300 $\underline{0081}$

Yoshinaga, N., Ohshima, F., Matsuki, S., Tanaka, M., Kobayashi, T., Ibuki, H., Asano, K., Kobori, O., Shiraishi, T., Ito, E., Nakazato, M., Nakagawa, A., Iyo, M., \& Shimizu, E. (2013). A preliminary study of individual cognitive behavior therapy for social anxiety disorder in Japanese clinical settings: A single-arm, uncontrolled trial. BMC Research Notes, 6(74), 1-8. https://doi.org/10.1186/1756-0500-6-74 